\title{
O ensino de fração no Curso do Artigo 99 da Universidade de Cultura Popular: vestígios de uma matemática a ensinar e matemática para ensinar
}

The teaching of fractions in the Article 99 Course of the Popular Culture University: traces of a mathematics to teach and mathematics for teaching

La enseñanza de las fracciones en el Curso Artículo 99 de la Universidad de la Cultura Popular: trazos de una matemática a enseñar y de una matemática para enseñar

Janine Marques da Costa Gregorio Universidade Federal de Santa Catarina - UFSC Florianópolis, Santa Catarina, Brasil

E-mail: janinemcosta13@gmail.com Orcid: 0000-0001-8704-0870

Jonathan Machado Domingues Universidade Federal de Santa Catarina- UFSC

Florianópolis, Santa Catarina, Brasil E-mail: domingues.j.m@posgrad.ufsc.br Orcid: 0000-0002-1065-5655

David Antonio da Costa Universidade Federal de Santa Catarina - UFSC Florianópolis, Santa Catarina, Brasil

E-mail: david.costa@ufsc.br Orcid: 0000-0003-4493-9207

Resumo: Este artigo dialoga com uma pesquisa de mestrado em andamento no PPGECTUFSC, assim como é a continuação de um estudo que investigou as orientações pedagógicas e didáticas no ensino de fração, vistas nas obras do Professor Manoel Jairo Bezerra. Tem-se por objetivo encontrar vestígios de uma matemática a ensinar e matemática para ensinar fração, 
apreendidos nas produções de Bezerra, através das materialidades do Curso do Artigo 99 da Universidade de Cultura Popular. Este trabalho procurou responder à questão norteadora: Quais foram as orientações didáticas pedagógicas propostas por Bezerra para o ensino de fração no Curso do Artigo 99 da Universidade de Cultura Popular? Salienta-se que, tendo cunho histórico, o trabalho se pautou na História Cultural e em interlocuções teóricas metodológicas que mobilizam os conceitos de matemática a ensinar e matemática para ensinar. Em síntese, infere-se que as orientações propostas por Bezerra para o ensino de fração acompanharam as produções do docente ao longo do espaço/tempo.

Palavras-Chave: História da educação matemática. Manoel Jairo Bezerra. Blocofrações.

Abstract: This article dialogues with a master's research in progress at PPGECT-UFSC, as well as, it is a continuation of a study that investigated the pedagogical and didactic orientations in teaching fractions seen in the works of Professor Manoel Jairo Bezerra. It aims to find traces of a mathematics to teach and mathematics for teaching fraction apprehended in Bezerra's productions, through the materialities of the Article 99 Course of the Popular Culture University. This paper sought to answer the guiding question: What were the didactic-pedagogical orientations proposed by Bezerra for the teaching of fractions in the Article 99 Course of the Popular Culture University? It is noteworthy that, having a historical nature, the work was based on Cultural History and on theoretical and methodological interlocutions that mobilize the concepts of mathematics to teach and mathematics for teaching. In summary, it is inferred that the guidelines proposed by Bezerra for the teaching of fractions followed the teacher's productions throughout time and space.

Keywords: History of mathematics education. Manoel Jairo Bezerra. Blocofractions.

Resumen: Este artículo dialoga con una investigación de maestría en curso en el PPGECTUFSC, así como, es una continuación de un estudio que investigó las orientaciones pedagógicas y didácticas en la enseñanza de las fracciones vistas en las obras del profesor Manoel Jairo Bezerra. Pretende encontrar las huellas de una matemática a enseñar y de una matemática para enseñar la fracción aprehendidas en las producciones de Bezerra, a través de las materialidades del Curso Artículo 99 de la Universidad de la Cultura Popular. Este trabajo buscó responder a la pregunta guía: ¿Cuáles fueron las orientaciones didáctico-pedagógicas propuestas por Bezerra para la enseñanza de las fracciones en el Curso Artículo 99 de la Universidad de la Cultura Popular? Cabe destacar que, al tener un carácter histórico, el trabajo se basó en la Historia Cultural y en interlocuciones teóricas y metodológicas que movilizan los conceptos de matemática a enseñar y matemática para enseñar. En síntesis, se infiere que las orientaciones propuestas por Bezerra para la enseñanza de las fracciones acompañaron las producciones del profesor a lo largo del tiempo y del espacio.

Palabras-chave: História de la educación matemática. Manoel Jairo Bezerra. Blocofracciones.

Recebido em $30 / 01 / 2021$

Aceito em $19 / 04 / 2021$ 


\section{CONSIDERAÇÕES INICIAIS}

Este texto versa sobre os desdobramentos do trabalho desenvolvido por Domingues, Gregorio e Costa (2020) que teve como objetivo encontrar vestígios de uma matemática a ensinar e a matemática para ensinar fração, apreendidos nas produções de Manoel Jairo Bezerra. Nesta esteira, infere-se que a temática do ensino de fração se apresenta como um lugar fértil para novas produções no campo da História da educação matemática (Hem), como podem ser vistos nos seguintes trabalhos: Alves (2020); Jandrey, Dias e Santos (2020); Laus (2020); Neves (2019); Trindade e Silva (2018), entre outros.

Através deste artigo, intenta-se investigar a matemática a ensinar e a matemática para ensinar fração, apreendidas no Curso do Artigo 99, da Universidade de Cultura Popular (UCP), que circulou no Diário de Pernambuco (1968).

De acordo com Maciel (2016), a UCP se trata de um projeto de teleducação, desenvolvido pelo Governo Federal, na sede das emissoras de televisão Continental e Tupi entre as décadas de 1960 e 1970. O projeto possui ingredientes de uma educação social, para todos, com o intuito de preparar os jovens e adultos para realizarem os Exames de Madureza ${ }^{1}$. Esse movimento formativo recebeu a nomenclatura de "Curso do Artigo 99" em razão da Lei de Diretrizes e Bases de 1961. No artigo 99 consta: "Aos maiores de dezesseis anos será permitida a obtenção de certificados de conclusão do curso ginasial, mediante a prestação de exames de madureza, após estudos realizados sem observância do regime escolar" (Decreto-lei n. $709,1969, \mathrm{~s} / \mathrm{p}$.).

Pontua-se que o projeto da UCP foi transmitido inicialmente por meio da Televisão Continental, como citado anteriormente, a qual tinha sede instalada no Rio de Janeiro. Maciel (2016) registra que ocorreram gravações de mais de 420 aulas, com

\footnotetext{
1 "O exame de madureza no Brasil foi criado no século XIX pelo Decreto 981/1890, e buscava, pela sua proposta inicial, atender a um público que, por diferentes motivos, não havia concluído os estudos em instituições regulares de ensino e que almejava galgar patamares mais elevados de escolaridade. $O$ exame surgiu concomitantemente à reforma Benjamim Constant, com o propósito de que os estudantes nele aprovados pudessem se candidatar a vagas em cursos superiores" (Oliveira \& Ferreira, 2015, p. 426).
} 
transmissões aos domingos. No decorrer do tempo, essa educação a distância começou a ser transmitida para outras emissoras além das fronteiras cariocas, e da TV Tupi, elas são: TV Itapoan de Salvador, TV Fortaleza, TV Vitória, TV Rádio Clube de Recife, TV Marajoara de Belém, TV Paraná, TV Piratini de Porto Alegre e TV Alterosa de Belo Horizonte.

Maciel (2016) afirma que nesse processo formativo ocorreram teleaulas das disciplinas: Ciências; Geografia; História; Matemática e Português. Os responsáveis pela produção dos artigos que circulavam nos jornais da época, assim como nas produções dos materiais didáticos, eram: Cadmo Bastos e Roberto S. Paulo (Ciências); Tharceu Nehrer e Nilo Garcia (Geografia); Renato Azevedo e José Sales Tiné (História); coordenação Dinamérico Pereira Pombo e supervisão Judith Brito de Paiva e Souza, na cadeira de Português; e, por fim, na cadeira de Matemática, o professor catedrático Manoel Jairo Bezerra.

Pode-se levantar a hipótese que a UCP foi um plano experimental de trabalhos formativos, com a finalidade de inserir grupo de estudantes afastados das atenções vindas de políticas públicas: jovens e adultos, com razões de não prosseguirem na trajetória escolar, como corrobora a resolução n. 1, de 11 de março de 2016, que estabelece Diretrizes e Normas Nacionais para a oferta de programas e cursos de Educação Superior na modalidade a distância.

Maciel (2016) afirma que:

Em buscas por arquivos governamentais e privados, por cerca de 10 anos, não foi encontrado nenhum vestígio desse programa. O que foi localizado eram apenas falas de antigos funcionários da Fundação Centro Brasileiro de Televisão Educativa, cuja sucessora foi a Associação de Comunicação Roquette Pinto (Maciel, 2016, p. 94).

Este texto se apoia nos pressupostos da História Cultural. Considera os jornais em circulação para o desenvolvimento desta investigação como objeto histórico e fonte de pesquisa.

Ao que destaca a importância do lugar em que a notícia se encontra inserida, sendo imprescindível problematizar as alterações retratadas pelos jornais com o 
passar do tempo, Luca (2005, p. 132) elenca que "[...] historicizar a fonte requer ter em conta, portanto, as condições técnicas de produção vigentes e a averiguação, dentre tudo que se dispunha, do que foi escolhido e por quê".

A presente tessitura se estrutura, para além das considerações iniciais aqui elencadas, em uma explanação do referencial teórico metodológico. Em seguida, busca-se investigar uma matemática a ensinar e matemática para ensinar fração, apreendidas a partir dos materiais didáticos produzidos pelo professor Manoel Jairo Bezerra, no Curso do Artigo 99 da Universidade de Cultura Popular. Ao final desta escrita são apresentados alguns encaminhamentos futuros, que se encontram em diálogo com uma pesquisa de nível de mestrado em desenvolvimento no Programa de Pós-Graduação em Educação Científica e Tecnológica (PPGECT) da Universidade Federal de Santa Catarina (UFSC).

Em linhas de síntese, a questão de norteadora deste texto é: Quais foram as orientações didáticas pedagógicas propostas por Manoel Jairo Bezerra para o ensino de fração no Curso do Artigo 99 da Universidade de Cultura Popular?

\section{INTERLOCUÇÕES TEÓRICAS METODOLÓGICAS}

O presente artigo se vincula aos estudos provindos da História Cultural, a qual compreende que para realização de uma investigação histórica deve haver marcação de um objeto, de um período, e de um lugar (Certeau, 2017). Nesta esteira, Certeau (2017, p. 69) aponta que, em história, "tudo começa com o gesto de separar, de reunir, de transformar em documentos certos objetos distribuídos de outra maneira".

Para este texto, reúnem-se as prescrições do Curso do Artigo 99, publicadas no Jornal Diário de Pernambuco, 1968, e coteja-se com outras produções de Manoel Jairo Bezerra. Institucionaliza-se uma operação historiográfica constituída por um lugar social, uma prática e uma escrita (Certeau, 2017).

Este artigo se apoia também nos estudos desenvolvidos pela Equipe de Recherche en Histoire Sociale de l'Éducation (ERHISE), em especial, em relação à caracterização de dois saberes que se encontram na construção histórica da profissão 


\section{Universidade Federal da Grande Dourados}

docente: saberes a ensinar e saberes para ensinar. Os saberes para ensinar, que têm por especificidade a docência, ligam-se àqueles saberes próprios para o exercício da profissão docente, que, em outros termos, são as ferramentas de trabalho do professor; em contrapartida, os saberes a ensinar, que representam o objeto de trabalho do professor, são ligados à instituição de ensino. Os saberes "a ensinar" e "para ensinar" se articulam (Hofstetter \& Schneuwly, 2017), podendo ainda serem tratados como categorias conceituais referentes aos saberes profissionais do professor.

Para os autores genebrinos, o conhecimento é ligado à experiência de cada um, na ordem do pessoal. Já os 'saberes' são objetos de ordem despersonificada de modo distinto daqueles tratados nos estudos que abordam o ponto de vista da prática, a sua mobilização no fazer, na ação (Hofstetter \& Schneuwly, 2017).

No Brasil, em especial, é possível identificar, através dos estudos desenvolvidos pelos pesquisadores que compõem o Grupo Associado de Estudos e Pesquisas sobre História da Educação Matemática (GHEMAT-BRASIL), um refinamento em relação às categorias adotadas pelos genebrinos: os saberes a ensinar e saberes para ensinar impulsionaram os seguintes verbetes: matemática a ensinar e matemática para ensinar.

Acerca da apreensão dos saberes a ensinar e saberes para ensinar, tem-se como hipótese teórica que os saberes do professor que ensina matemática, no âmbito específico deste ensino, constituem-se pelos dois conjuntos de saberes: matemática a ensinar e matemática para ensinar. Segundo Bertini, Morais e Valente (2017), tais saberes levam à matemática a ensinar e à matemática para ensinar, e relacionam-se aos saberes presentes na profissão deste professor.

Dessa forma, no tópico a seguir se busca responder o seguinte problema de pesquisa que norteia o presente artigo: Quais foram as orientações didáticas e pedagógicas propostas por Manoel Jairo Bezerra para o ensino de fração no Curso do Artigo 99 da Universidade de Cultura Popular? 


\section{ALGUNS APONTAMENTOS SOBRE O ENSINO DE FRAÇÃO A PARTIR DAS OBRAS DE MANOEL JAIRO BEZERRA}

Após a publicação do artigo "Matemática a ensinar e matemática para ensinar fração: algumas considerações das produções de Bezerra", (Domingues et al., 2020) no qual foi tratado sobre Blocofrações ${ }^{2}$, decidiu-se investigar e aprofundar as análises iniciadas em outras produções de Manoel Jairo Bezerra, relacionadas ao conteúdo de frações.

Os conceitos saberes para ensinar e saberes a ensinar são mobilizados nas análises do artigo "Matemática", de autoria de Manoel Jairo Bezerra, publicado no jornal Diário de Pernambuco, em 27 de dezembro de 1968, na parte destinada ao Curso do Artigo 99, da UCP, em que eram publicadas apostilas do programa às sextas-feiras e sábados, cujas edições o aluno poderia colecionar para acompanhamento de todo o curso. O artigo possui o subtítulo "Frações", elencando oito tópicos para tratar do assunto (Bezerra, 1968b). E o subtítulo "Operações com fração", com mais três tópicos (Bezerra, 1968c).

Pontua-se que, a partir de um breve levantamento na Hemeroteca Digital ${ }^{3}$, foi possível identificar apostilas que corroboram com as rubricas elencadas por Maciel (2016). Dessa forma, para o desenvolvimento deste estudo se recorreu às seguintes rubricas: frações ${ }^{4}$ (1. Noção de fração; 2. Números fracionários; 3. Frações decimais e ordinárias; 4. Frações próprias e impróprias; 5 . Simplificação de frações; 6 . Números mistos; 7. Redução de frações ao mesmo denominador; e 8. Comparação de frações).

\footnotetext{
2 É um material manipulável utilizado para o ensino de fração. Essa materialidade pedagógica é constituída por dois grupos A e B. Dito isso, o Grupo A é composto de seis cubos azuis claros de $4 \mathrm{~cm}$ de aresta (são os inteiros) e quatro paralelepípedos azuis escuros de $4 \mathrm{~cm} \times 4 \mathrm{~cm} \times 2 \mathrm{~cm}$ (são os meios). O Grupo B é composto de quatro paralelepípedos brancos de $2 \mathrm{~cm} \times 2 \mathrm{~cm} \times 4 \mathrm{~cm}$ (são os quartos) e 8 cubos de 2cm de aresta (são os oitavos) (Domingues et al., 2020; Bezerra, 1962).

3 Para maiores informações, consultar: https://bndigital.bn.gov.br/hemeroteca-digital/. Acesso em 27 jan. 2021.

$4 \quad$ Disponível em: http://memoria.bn.br/DocReader/DocReader.aspx?bib=110523 06\&Pesq=\%22Manoel\%20Jairo\%20B ezerra\%22\&pagfis $=70408$, Acesso em: 27 jan. 2021. Destarte, pontua-se que a mesma ocorrência pode ser encontrada idêntica em outros jornais da época.
} 
Além do mais, utilizou-se: Operações com frações ${ }^{5}$ (9. Adição; 10. Subtração; 11. Multiplicação; 12. Divisão).

Assim, busca-se no texto tratar sobre as orientações deixadas por Manoel Jairo Bezerra acerca do ensino de fração. Não estão claramente postos os indícios da matemática para ensinar na obra de Bezerra (1968b), mas a respeito da noção de fração no artigo publicado no jornal, supõe-se que tenha sido usado um cubo de sabão. Tal indicação de uso de materiais da vida real do aluno aparece de maneira recorrente nas escritas de Manoel Jairo Bezerra, tentando sempre relacionar o ensino com o cotidiano do aluno, demonstrando uma objetivação no ensino de fração. Tal situação pode ser vista em Bezerra (1962, 1968a, 1968b, 1968c). Pode-se, então, afirmar que há ingredientes formativos que se encontram associados à contextualização do ensino de fração com o dia a dia do discente e ser feita uma apreensão de uma matemática para ensinar.

Nessa esteira, Bezerra (1968b) em sua primeira indicação do uso do Blocofrações sugere realizar a divisão de um cubo de $4 \mathrm{~cm}$ de aresta em partes iguais. Após, que o mesmo seja dividido em duas, quatro ou oito partes. Iniciando-se com a divisão por quatro, ao tomar uma parte, ela representa um quarto do cubo, indicado pela fração $\frac{1}{4}$. Ao se tomar duas partes, obtêm-se dois quartos ou $\frac{2}{4}$. Assim, surge a ideia de denominador, isto é, algarismo associado a quantidades de partes em que o inteiro foi dividido. A sequenciação e gradação no ensino de fração tomada por Bezerra (1968b) pode ser compreendida como elementos de uma matemática a ensinar, sistematizada em suas obras. Em outras palavras, compreende-se como sequenciação a organização em sequência, sucedendo-se uma atividade após a outra. Em contrapartida, a gradação denomina a marcha, isto é, estabelece-se uma ordem tomada do mais simples para o mais complexo.

\footnotetext{
${ }^{5}$ Disponível em: http://memoria.bn.br/DocReader/DocReader.aspx?bib=110523 06\&pesq=\%22Manoel\%20Jairo\%20B ezerra\%22\&pasta=ano\%20196\&pagfis=70430. Acesso em: 27 jan. 2021. Destarte, pontua-se que, a mesma ocorrência pode ser encontrada idêntica em outros jornais da época.
} 
Esta abordagem também foi sistematizada por Manoel Jairo Bezerra no artigo publicado por ele, na Revista do Ensino - Rio Grande do Sul (Domingues et.al, 2020). Assim, a partir da atenção dispensada ao artigo em relação ao ensino de fração, podem-se observar recomendações para utilização de um acessório manipulável. O que sugere indícios de orientações didáticas pedagógicas propostas por Manoel Jairo Bezerra, acerca do ensino de fração.

De forma semelhante às instruções presentes no Curso do Artigo 99 no qual ele indica o uso de sabão, na Revista do Ensino, Manoel Jairo Bezerra instrui os discentes a realizarem a contagem dos blocos que compõem o Blocofrações, indicando-Ihe a ordem de tamanho. A manipulação das peças resultará em análise daquelas que cabem na caixa, referindo-se à formação de dois grupos destacados por uma "divisória" entre eles: Grupo A [peças laranjas e azuis] e o Grupo B [peças brancas e amarelas] (ver Figura 1) (Domingues et al., 2020).

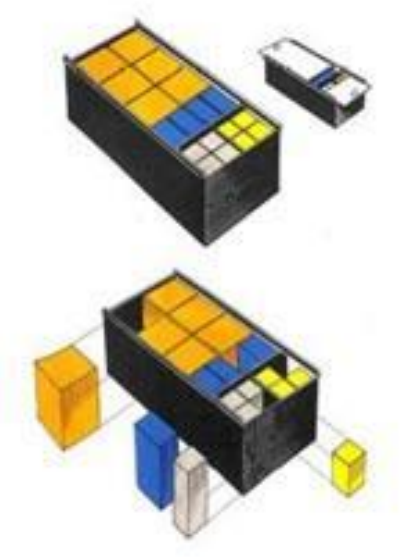

Figura 1 - Blocofrações: um acessório para o ensino de fração Fonte: Bezerra, 1968a, p. 80.

Estas orientações elaboradas por Manoel Jairo Bezerra, circuladas nos materiais produzidos por ele, e articuladas entre um saber a ensinare para ensinar sistematizam uma matemática para ensinar fração. Trata-se de um movimento que torna o saber a ensinar ensinável. Segundo Valente (2018, p. 74) “(...) a matemática para ensinar, é também fruto de processo de elaboração histórica e não constitui um saber de cultura geral". 


\section{Universidade Federal da Grande Dourados}

Como já mencionado nos tópicos anteriores nesta investigação, a análise desse processo histórico toma como fonte os artigos dos jornais em relação ao Curso do Artigo 99, da UCP, e coteja-se com outras fontes produzidas por Manoel Jairo Bezerra para o ensino de fração nos múltiplos níveis de ensino. Dessa forma, infere-se que, como mencionado no artigo do jornal, as indicações da utilização do cubo de sabão, desde a realização da divisão da materialidade mencionada até chegar a uma indicação de uma fração, são ações próprias de uma matemática para ensinar fração.

À vista disso, considerando o cubo de sabão como recurso didático, avança-se na constituição do conhecimento matemático (Valente et al., 2017), resultando assim, um saber profissional no exercício da docência, uma ferramenta no trabalho do professor.

Nesse percurso, Manoel Jairo Bezerra acaba indicando que, para o ensino de frações, devem-se mobilizar os blocos relacionados às seguintes frações: $\frac{1}{2}, \frac{1}{4}$ e $\frac{1}{8}$, realizando-se uma espécie de comparação entre eles: um bloco laranja é equivalente a dois blocos azuis; um bloco azul é equivalente a dois blocos brancos, um bloco branco é equivalente a dois blocos amarelos. De forma recíproca, dois blocos amarelos são equivalentes a um bloco branco. Quatro blocos amarelos são equivalentes a um bloco azul. E finalmente oito blocos amarelos são equivalentes a um bloco laranja. Associando estas comparações e representando-as em frações, os números 2, 4, 8 se referem aos denominadores, que têm a finalidade de nomear cada parte do inteiro (Bezerra, 1968a), e retratam a quantidade de partes em que ocorreu a divisão do bloco maior, intitulado como unidade.

Pode-se observar no material produzido por Bezerra (1962; 1968b) que, ao iniciar o conteúdo de fração, é necessário explicar algumas definições, contemplando aos poucos o conteúdo desejado, sistematizando-o. Dessa maneira, a partir das buscas de outras produções de Manoel Jairo Bezerra, como foi apresentado anteriormente, caderno MEC (Bezerra, 1968a) e Revista do Ensino (Bezerra, 1962), em referência ao ensino de fração, existem ingredientes que se alinham à proposta deste professor no Curso do Artigo 99, da UCP.

Bezerra (1968b) indica que "o número fracionário pode ser considerado como o quociente da divisão do numerador pelo denominador" (Bezerra, 1968b, p. 15), que 


\section{Universidade Federal da Grande Dourados}

representa uma ou mais partes da unidade. Ao tratar acerca do numerador e denominador como partes de uma fração, representando quantidades, pode-se inferir que estes elementos formam uma matemática a ensinar fração, contemplando o conteúdo.

Avançando nas orientações, Bezerra (1968b) apresenta as frações decimais: cujos denominadores correspondem a potências de 10, exemplificando com $\frac{1}{10} \mathrm{e} \frac{7}{100} \mathrm{e}$ as frações ordinárias, que são as demais frações, tais como $\frac{3}{4} \mathrm{e} \frac{7}{20}$.

Já as frações próprias e impróprias, conteúdos abordados no caderno MEC (Bezerra6 $\left.{ }^{6}, 1968 a\right)$, são também tratadas no artigo do jornal. Segundo o autor, as frações em que o numerador é maior ou igual ao denominador são nominadas como frações impróprias; aquelas em que o numerador é menor que o denominador, são designadas frações próprias. Infere-se que os vestígios das orientações acerca do ensino de fração, proposto por Manoel Jairo Bezerra, foram deveras importantes.

Recorrendo-se a outras materialidades apresentadas por Bezerra (1968a), com intuito de evidenciar vestígios que corroboram com o ensino de fração proposto no Curso do Artigo 99 da UCP, tem-se o Caderno MEC (1968a). Tal material aponta problematizações das frações próprias e impróprias.

Nas prescrições do Curso, Manoel Jairo Bezerra indica algumas perguntas que destacam esses conceitos: "uma fração de numerador maior ou igual ao denominador é uma fração imprópria?" (Bezerra, 1968a, p. 38), além do mais, "algumas frações impróprias podem ser equivalentes a números inteiros?" (Bezerra, 1968a, p. 38). Na Figura 2, observam-se as frações que categorizam cada parte do acessório blocofrações.

\footnotetext{
${ }^{6}$ Para maiores informações acessar: Domingues et al. (2020) e Bezerra (1968).
} 

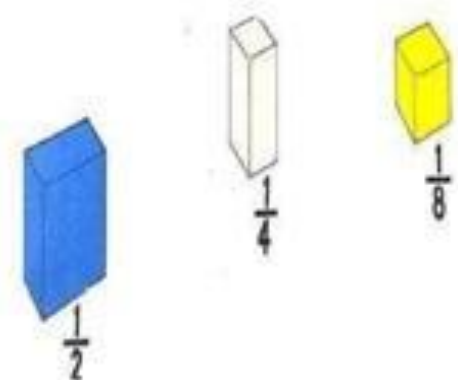

Figura 2 - Frações das peças do Blocofrações Fonte: Bezerra, 1968a, p.81.

Seguindo os subtópicos de Bezerra (1968b), em relação à simplificação de frações, considera-se um cubo de sabão como unidade, tal que é possível dividi-lo em duas, quatro ou oito partes, havendo múltiplas possibilidades de representá-las, tais como: $1, \frac{2}{2}, \frac{4}{4}$ ou $\frac{8}{8}$, respectivamente. Identifica-se que a fração não altera se forem multiplicados ou divididos ambos os termos pelo mesmo número natural. A questão da simplificação de fração é tratada por Manoel Jairo Bezerra em muitos de seus trabalhos, inclusive explorada por Domingues et al. (2020), em cuja pesquisa a sistematização de tal conteúdo é novamente visível. Após realizar a simplificação de uma fração, tem-se que a encontrada em números menores é uma fração irredutível. Como pode ser visto no exemplo abaixo:

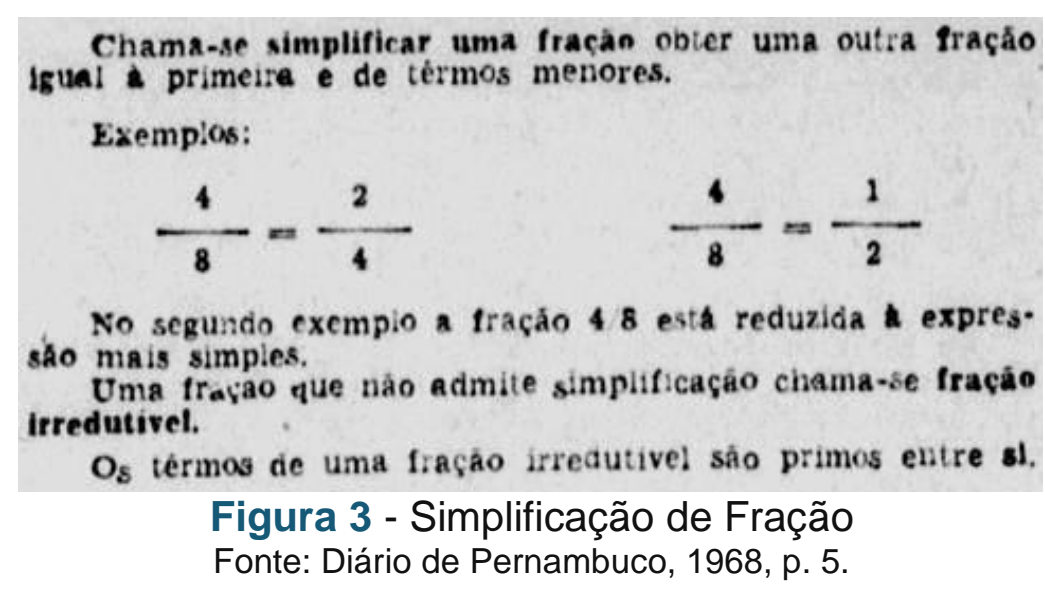

Continuando nesse percurso, em relação à simplificação de fração, veem-se indícios de uma sistematização de saberes, em especial em relação à matemática a ensinar e matemática para ensinar. Corroborando-se com outras análises das 


\section{Universidade Federal da Grande Dourados}

materialidades produzidas por Manoel Jairo Bezerra é possível encontrar vestígios das matemáticas: a ensinar e para ensinar, como pode ser visto em Domingues e Costa (2020), França (2019), entre outros.

De acordo com Domingues et al. (2020, p. 13), em referência à análise sobre as obras produzidas por Manoel Jairo Bezerra, especificamente, em relação à simplificação de frações, "(...) tem-se que ao multiplicar ou dividir ambos os termos de uma fração, por um mesmo número, o valor da fração não se altera", além do mais, "(...) evidencia que é possível observar que a peça laranja, que representa a unidade, cabe exatamente em cada uma das divisões menores da caixa" (p. 13).

As duas peças azuis, que representam $\frac{1}{2}+\frac{1}{2}=\frac{2}{2}$, torna-se igual a 1", ou seja, somase duas metades, considerando-se para a representação numérica. Por mais “(...) O mesmo ocorre com quatro peças brancas, no qual $\frac{1}{4}+\frac{1}{4}+\frac{1}{4}+\frac{1}{4}=\frac{4}{4}$, e simplifica-se a 1" (p. 13). O que se entende é o tratamento de unidades que são ora representadas por inteiros, ora representadas por partes. Em outras palavras, somar frações de denominador comum se assemelha a somar números naturais. Neste caso, Bezerra (1968b) sintetiza em suas produções que a soma de frações pode ser considerada como soma de 'coisas' iguais.

Avança-se para as definições de números mistos, maneira na qual é possível escrever as frações impróprias, onde o numerador é maior que o denominador (Figura $4)$. 
A fração impropria $9 / 4$ pode ser escrita

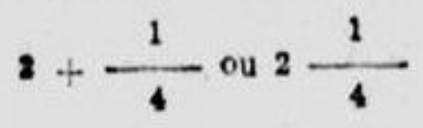

Exempios de numeros mistos:

$3 \frac{1}{4} \cdot 2 \frac{4}{5}$

\section{OBSERVAÇOES:}

a) A some de um numero natural com uma fraçâo propria, e um numero misto.

b) Todo numero misto e equivalente a uma fraçáo innpropria.

c) Para transformar uma fração tmpropria em numero misto. basta dividir o numerador peio denominador.

Figura 4 - Número misto

Fonte: Diário de Pernambuco,1968, p.5.

Bezerra (1968b) também apresenta detalhes acerca da redução de frações ao mesmo denominador, em que instrui transformar a fração em outras do mesmo valor com o mesmo denominador, como se pode observar nas orientações da Figura 5.

Finalizando as explanações de Bezerra (1968b), percebe-se a comparação de frações, em que o autor afirma que "frações que têm o mesmo denominador, a maior é a que tiver o maior numerador" (Bezerra, 1968b, p. 15). Assim, verificam-se indícios de uma matemática a ensinar, os quais se apresentam como orientações acerca do ensino de fração, e como resposta a questão inicial. 


\section{Universidade Federal da Grande Dourados}

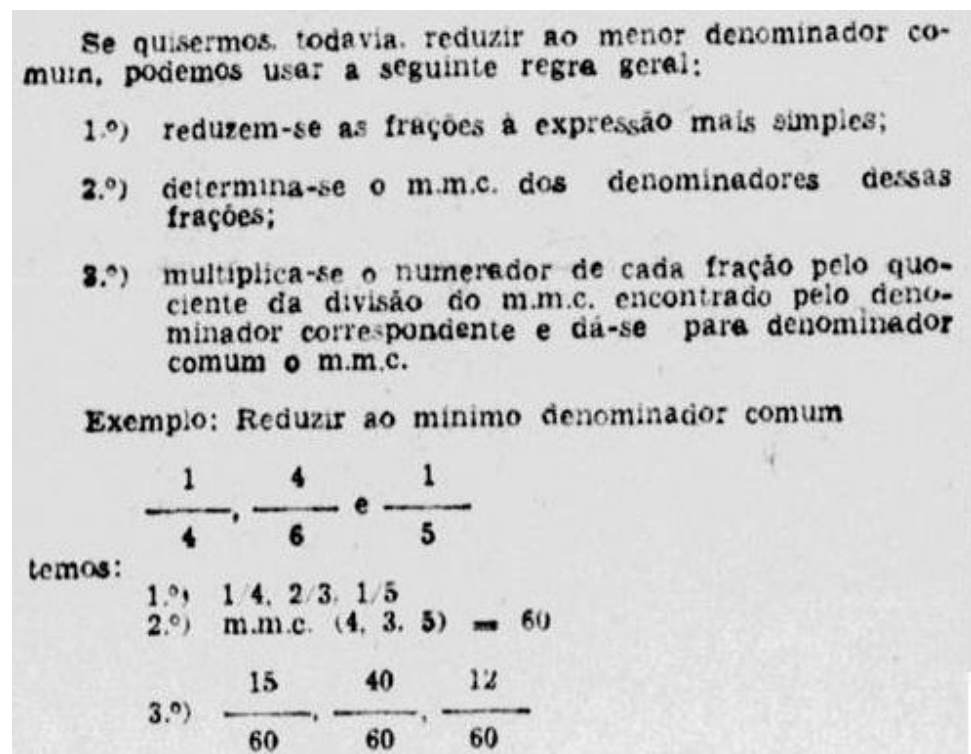

Figura 5 - Redução de fração ao mesmo denominador Fonte: Diário de Pernambuco, 1968, p. 5.

Destarte, o material produzido por Manoel Jairo Bezerra engloba contribuições acerca do ensino de frações, tanto à formação de professores, quanto ao ensino da matemática no ensino primário/secundário, como pode ser visto em: Domingues e França (2020); Domingues e Costa (2020); Domingues (2019), entre outros. Os conteúdos são explorados de maneira recorrente em suas produções, o que é possível inferir que existe uma sistematização de seu trabalho, buscando uma objetivação do ensino de fração, tratando-o em uma sequenciação, de maneira gradual por meio das orientações didáticas pedagógicas.

Na edição do jornal n. 14491, o qual apresenta a apostila n. 14, do Curso do Artigo 99, encontra-se outro texto que trata sobre o ensino de fração, detalhadamente acerca das operações com frações, também de autoria de Bezerra (1968c), aplicando os conceitos tratados no artigo anterior. O autor o inicia tratando da adição, no qual aborda acerca da soma de inteiros com fração própria, com número misto, com fração imprópria, até chegar na soma de frações de mesmo denominador e de denominadores diferentes. Bezerra (1968c) busca exemplificar a soma de elementos iguais, vinculada a um mesmo denominador, para que seja então realizada a operação, e assim, de maneira gradual, vai tratando o ensino de fração, avançando aos poucos, do ponto de vista de conteúdo matemático. 
Ao cotejar as informações publicadas na Revista do Ensino/RS, especificamente no artigo escrito por Bezerra (1962), também há referência à operação da adição com frações. Apoiando-se no material didático blocofrações, o autor percorre os seguintes caminhos: soma de um inteiro com fração, de inteiros com números mistos e com frações, após, frações com denominadores iguais, em seguida, de frações com denominadores diferentes. Tal sequenciação, semelhante ao que é tratado na produção de Bezerra (1968), apresenta elementos que determinam uma matemática a ensinar fração, sistematizando e objetivando o ensino de fração e suas orientações.

Ao explorar a subtração, Bezerra (1968c) trata da diferença entre frações de mesmo denominador, da subtração de frações com denominadores diferentes, em subtrair um inteiro de uma fração própria, da subtração de um número inteiro de um número misto. Esta ordem na abordagem destes conteúdos também pode ser vista no artigo que trata do blocofrações (Bezerra, 1962), indicando a sistematização de Manoel Jairo Bezerra no ensino das operações com frações. Trata-se da sequenciação no ensino das frações e, verifica-se o quanto o ensino de fração se torna objetivado.

Tomando a multiplicação e divisão, viu-se também que Manoel Jairo Bezerra trata do produto e do quociente de: número inteiro com frações, número inteiro com número misto, duas frações, número misto com fração e dois números mistos, tudo isso, objetivando as operações com frações, de maneira a exemplificar as operações possíveis.

As primeiras análises realizadas na documentação do Curso do Artigo 99, da UCP, em diálogo com outras fontes desenvolvidas por Manoel Jairo Bezerra, à luz de Hofstetter e Schneuwly (2017), e tendo como categoria histórica: matemática a ensinar e matemática para ensinar, infere-se que o entendimento que Manoel Jairo Bezerra sistematizou em relação ao ensino de fração, indicado desde a publicação na Revista do Ensino, em 1962, é possível identificar representações da continuação dessa objetivação no Curso do Artigo 99, da UCP, como nas produções anteriores do mesmo. Dessa forma, podem-se apreender elementos que caracterizam uma matemática para ensinar e uma matemática a ensinar, começando aos poucos, 


\section{Universidade Federal da Grande Dourados}

trabalhando com os números inteiros, de maneira gradual, e sequenciada o ensino de fração, sistematizado em suas produções.

Com todos esses subsídios, buscou-se responder à questão inicial, apresentando elementos que tratassem de tais orientações acerca do ensino de fração, objetivados através da sistematização de Manoel Jairo Bezerra em suas produções vestígios de uma matemática a ensinar e matemática para ensinar, no Curso do Artigo 99, da Universidade de Cultura Popular.

\section{ALGUMAS CONSIDERAÇÕES E ENCAMINHAMENTOS FUTUROS}

Em linhas de síntese, a presente tessitura teve como objetivo tratar as orientações de Manoel Jairo Bezerra sobre o ensino de fração, explorando a matemática a ensinar e a matemática para ensinar, através de materiais produzidos por ele, e teve como pergunta norteadora: Quais foram as orientações didáticas pedagógicas propostas por Manoel Jairo Bezerra para o ensino de fração no Curso do Artigo 99 da Universidade de Cultura Popular?

Neste texto, atentou-se ao material publicado por Bezerra (1968b), no Diário de Pernambuco - 1968, utilizado pelo programa do Curso do Artigo 99, da UCP, que tinha como público-alvo, jovens e adultos que prestariam os Exames de Madureza. O artigo apresenta orientações acerca do ensino de fração.

Dessa forma, as orientações metodológicas e didáticas pedagógicas vistas nas produções de Manoel Jairo Bezerra, sendo sistematizadas e objetivadas, de forma recorrente aparecem em diversas publicações em períodos que percorrem quase uma década. Tais orientações podem ser vistas em livros, que tratam da formação de professores e que se encontram no Centro de Memória do Instituto Superior de Educação do Rio de Janeiro, bem como, ratificadas na materialidade do Curso do Artigo 99, da UCP.

Assim, as apostilas que circulavam nos jornais da época revelam o ensino de fração com a utilização de um acessório que se encontrava no cotidiano dos alunos: 
o sabão, que realizava as funções dos cubos (blocos) do material Blocofrações material didático estruturado para o ensino de matemática.

No artigo que circulou nos jornais referente ao curso foram abordados os seguintes conteúdos que se encontravam presentes no ensino de fração: simplificação de fração, número mistos, redução de fração, problemas sobre frações, dentre outros. Destarte, em relação à matemática a ensinar e à matemática para ensinar fração, apreendidas na fonte analisada, observou-se uma articulação entre ambas, não sendo tratadas separadamente. Infere-se que as orientações propostas por Bezerra para o ensino de fração acompanharam as produções do docente ao longo do espaço/tempo.

Por esta pesquisa se encontrar em andamento e já se possuir o inventário das apostilas publicadas nos jornais sobre o ensino de fração, fica o compromisso de continuidade ao movimento de busca a documentos históricos, tais como a apostila física e outros, que poderão elucidar as questões que tratam sobre o ensino de fração.

\section{REFERÊNCIAS}

Alves, L. I. (2020). Ensino de frações: antes ou depois dos decimais? Um estudo a partir de revistas pedagógicas. Acervo - Boletim do Centro de Documentação do Ghemat-SP, São Paulo, 2(2), 81-96. Recuperado de http://acervo.ghemat.com.br/index.php/ACERVO-GHEMAT/article/view/31/8

Bertini, L. F., Morais, R. dos S. \& Valente, W. R. (2017). A matemática a ensinar e a matemática para ensinar: novos estudos para a formação de professores. São Paulo: Editora Livraria da Física.

Bezerra, M. J. (1962). Blocofrações. Revista do Ensino, Porto Alegre, 1962, 86, 29 32. Recuperado de https://repositorio.ufsc.br/handle/123456789/127654 


\section{Universidade Federal da Grande Dourados}

Bezerra, M. J. (1968a). Caderno MEC Aritmética. Fundação Nacional de Material Escolar/ Ministério da Educação e Cultura, Rio de Janeiro. Recuperado de https://repositorio.ufsc.br/handle/123456789/160283

Bezerra, M. J. (1968b). Matemática. In Diário de Pernambuco - 20 de dezembro de 1968 - p. 8 - Edição 14490, 1968. Recuperado de

http://memoria.bn.br/DocReader/DocReader.aspx?bib=029033 14\&pesq=\%22M anoel\%20Jairo\%20Bezerra\%22\&pasta=ano\%20196\&pagfis=66151

Bezerra, M. J. (1968c). Matemática. In O Jornal (RJ) - 21 de dezembro de 1968 - p. 10 - $\quad$ Edição 14491, $1968 . \quad$ Recuperado de http://memoria.bn.br/DocReader/DocReader.aspx?bib=110523 06\&Pesq=\%22M anoel\%20Jairo\%20Bezerra\%22\&pagfis $=70430$

Certeau, M. (2017). A Escrita da história (3. ed.). Tradução de Maria de Lourdes Menezes. Rio de Janeiro: Forense Universitária.

Decreto-lei n. 709, de 28 de julho de 1969 (1969). Dá nova redação ao art. 99, da Lei n. 4.024, de 20 de dezembro de 1961. Brasília, DF. Recuperado de https://presrepublica.jusbrasil.com.br/legislacao/126057/decreto-lei-709-69

Domingues, J. M. (2019) A obra de Jairo Bezerra: Em busca dos saberes da profissão docente (1958) (Monografia Curso de Pedagogia) - Universidade do Estado do Rio de Janeiro, Rio de Janeiro. Recuperado de https://repositorio.ufsc.br/handle/123456789/212947

Domingues, J. M \& Costa D. A. (2020) Trajetória de Manoel Jairo Bezerra: saberes, expertise e formação docente. In: Anais XVIII Seminário Temático. Cuiabá: UNIC. 
Domingues, J. M. \& França, D. M. A. (2020) Didática Especial da Matemática: em busca dos saberes da profissão docente. Revista de História da Educação Matemática, $\quad$ v. $\quad 6, \quad 170-184 . \quad$ Recuperado de https://repositorio.ufsc.br/handle/123456789/212600

Domingues, J. M., Gregorio, J. M. C. \& Costa, D. A. (2020). Matemática a ensinar e matemática para ensinar fração: algumas considerações das produções de Bezerra. $\quad$ 10(3), 3-18. Recuperado de https://aplicacoes.ifs.edu.br/periodicos/index.php/caminhos da educacao mate $\underline{\text { matica/issue/view/53 }}$

França, D. M. (2019). Saber profissional do professor que ensina matemática: o caso do CFPEN (1966 a 1971). REVISTA COCAR (ONLINE), v. 6, 189-207. Recuperado de https://repositorio.ufsc.br/handle/123456789/200926

Jandrey, D., Dias, L. \& Simões, E. (2020). Saberes Para Ensinar Frações no Livro: O Ensino de Aritmética pela Compreensão. In Anais do ENAPHEM - Encontro Nacional De Pesquisa Em História Da Educação Matemática - ISSN 2596-3228, (5), $1-5$. Recuperado de

https://trilhasdahistoria.ufms.br/index.php/ENAPHEM/article/view/11191

Hofstetter, R. \& Schneuwly, B. (2017). Saberes: um tema central para as profissões do ensino e da formação. In R. Hofstetter \& W. R. Valente (Org.). Saberes em (trans) formação: tema central da formação de professores 1. Ed. São Paulo: Editora Livraria da Física. 
Laus, L. (2020). A História da educação matemática. ACERVO - Boletim Do Centro De Documentação Do GHEMAT-SP, 2(2), 97-112. Recuperado de http://acervo.ghemat.com.br/index.php/ACERVO-GHEMAT/article/view/32.

Luca, T. R. (2005). História dos, nos e por meio dos periódicos. In: PINSKY, C. B. (org.). Fontes Históricas, 111-153. São Paulo: Contexto.

Maciel, L. S. K. R. (2016). Universidade de Cultura Popular: história e semiótica. Boletim do LABEM. 7(13). Rio de Janeiro. Recuperado de http://www.labem.uff.br/novo/index.php/labem/article/view/85/87

Neves, K. C. R. (2019). Manuais preparatórios para os exames de admissão ao ginásio: uma análise sobre a fração. Histemat, 5(1), 132-149. Recuperado de http://www.histemat.com.br/index.php/HISTEMAT/article/view/254/198

Oliveira, K. R. V. \& Ferreira, M. Ferreira (2015) Exames de Madureza em Mato Grosso: registros da década de 1930. In Anais III EHECO. Recuperado de https://eheco2015.files.wordpress.com/2015/09/exames-de-madureza-em-matogrosso1.pdf

Trindade, D. de A. \& Silva, M. C. L. da. (2018). Grandezas: relações lidas no ensino de saberes aritméticos, 1890-1950. Zetetike, 26(3). https://doi.org/10.20396/zet.v26i3.8650703

Valente, W. R. (2018). O saber profissional do professor que ensina matemática: história da matemática a ensinar e da matemática para ensinar. In B. Dassie, \& D. A. Costa, História da educação matemática e formação de professores, 49-83. São Paulo: Editora Livraria da Física 
Valente, W. R., Bertini, L. F., Pinto, N. B \& Morais, R. S.00 (2017) A matemática na formação de professores e no ensino: processos e dinâmicas de produção de um saber profissional, 1890-1990. São Paulo: FAPESP.

na próxima página.)

\section{CONTRIBUIÇÕES DOS AUTORES}

1a autor: conceitualização; curadoria de dados; análise formal; investigação; metodologia; administração do projeto; supervisão; visualização; redação - rascunho original; redação - revisão e edição.

2o e 3 autor: conceitualização; curadoria de dados; análise formal; investigação; metodologia; administração do projeto; supervisão; visualização; redação - rascunho original; redação - revisão e edição. 